Article

\title{
Energy Production Analysis and Optimization of Mini-Grid in Remote Areas: The Case Study of Habaswein, Kenya
}

\author{
Andrea Micangeli ${ }^{1, *} \mathbb{D}^{\mathbb{D}}$, Riccardo Del Citto ${ }^{1, *} \mathbb{1}$, Isaac Nzue Kiva ${ }^{2,3}$, Simone Giovanni Santori ${ }^{1}$, \\ Valeria Gambino ${ }^{1}$, Jeremiah Kiplagat ${ }^{4}$, Daniele Viganò ${ }^{5}$, Davide Fioriti ${ }^{6}$ and Davide Poli ${ }^{6}$ \\ 1 DIMA, Department of Mechanical and Aerospace Engineering, University of Rome La Sapienza, \\ 00162 Roma, Italy; simonegiovanni.santori@uniroma1.it (S.G.S.); valeriagambino81@yahoo.com (V.G.) \\ 2 MOEP, Ministry of Energy and Petroleum of Kenya, Nairobi 30582, Kenya; isaac_kiva@yahoo.com \\ 3 JKUAT, Jomo Kenyatta University of Agriculture and Technology, Juja 00622, Kenya \\ 4 KPLC, Kenya Power and Lighting Company, Nairobi 30099, Kenya; jkiplagat@kplc.co.ke \\ 5 Departament of Physics \& IAC3, Universitat de les Illes Balears and Institut d'Estudis Espacials de \\ Catalunya, Palma de Mallorca, E-07122 Baleares, Spain; daniele.vigano@uib.eu \\ 6 DESTEC, Department Of Energy, Systems, Territory And Costruction Engineering, University of Pisa, \\ 56126 Pisa, Italy; davide.fioriti@ing.unipi.it (D.F.); davide.poli@unipi.it (D.P.) \\ * Correspondence: andrea.micangeli@uniroma1.it (A.M.); riccardo.delcitto@uniroma1.it (R.D.C.); \\ Tel.: +39-338-815-3787 (A.M.); +39-320-858-1571 (R.D.C.)
}

Received: 6 October 2017; Accepted: 29 November 2017; Published: 3 December 2017

\begin{abstract}
Rural electrification in remote areas of developing countries has several challenges which hinder energy access to the population. For instance, the extension of the national grid to provide electricity in these areas is largely not viable. The Kenyan Government has put a target to achieve universal energy access by the year 2020. To realize this objective, the focus of the program is being shifted to establishing off-grid power stations in rural areas. Among rural areas to be electrified is Habaswein, which is a settlement in Kenya's northeastern region without connection to the national power grid, and where Kenya Power installed a stand-alone hybrid mini-grid. Based on field observations, power generation data analysis, evaluation of the potential energy resources and simulations, this research intends to evaluate the performance of the Habaswein mini-grid and optimize the existing hybrid generation system to enhance its reliability and reduce the operation costs. The result will be a suggestion of how Kenyan rural areas could be sustainably electrified by using renewable energy based off-grid power stations. It will contribute to bridge the current research gap in this area, and it will be a vital tool to researchers, implementers and the policy makers in energy sector.
\end{abstract}

Keywords: hybrid mini-grid; rural electrification; renewable energy; rural development; energy access

\section{Introduction}

\subsection{Background of Study}

Reliable and affordable energy is recognized as an essential ingredient for socio-economic development and economic growth of any country to meet the basic human needs such as cooking, lighting and safe drinking water as well as to improve, among others, education, communication and productive activities.

According to the IEA (International Energy Agency) WEO (World Energy Outlook) 2017 estimates, almost 1.1 billion people - $14 \%$ of the global population — do not have access to electricity, and more than 
$95 \%$ of them are in sub-Saharan Africa and developing Asia. Kenya, despite making efforts to enhance electrification, only managed to reach an electrification rate of $47 \%$ in 2016 [1]. Looking at the current energy situation, there are still many challenges and weaknesses that affect the energy supply sector in Kenya. The main ones are: (i) low access to modern energy, especially for cooking, leading to high pressure on biomass resources; (ii) high cost of energy; (iii) energy demand increasing faster than the additional generation installation rate; (iv) high cost of rural electrification through grid extension due to the scattered nature of settlements; (v) frequent power outages and high system losses; and (vi) high dependence on imported petroleum fuels [2].

The Kenya Government has developed the Kenya Vision 2030 as the country's new development blueprint. The vision aims at transforming Kenya into a newly industrializing, middle-income country providing a high quality of life to all its citizens by the year 2030, and has identified provision of energy as the key to meet its goals. Aligned to this strategy document, Kenya has implemented the Energy Policy 2004, targeting to reach $40 \%$ electricity connectivity of the rural population by 2020 , and has subscribed the UN Sustainable Energy for All Initiative and the manifesto of Jubilee Coalition [3].

To pursue energy access for all, the efforts are focused both on energy transmission and distribution, and power generation. Since the energy transmission is capital intensive and has hitherto concentrated in high population density and high economic areas, the Kenya Government has installed off-grid diesel-based power stations and distribution mini-grids covering some remote rural areas for which the connection to the national transmission grid is not feasible.

The systems based on diesel generation installed by the Ministry of Energy and Petroleum to supply electricity to areas which are far from the national grid have experienced several challenges, such as: (i) the cost of fuel increases with the remoteness of the location due to logistic costs; (ii) on-site storage challenges; (iii) high operation and maintenance costs; and (iv) the gas emissions contribution to environmental pollution and global warming $\left(\mathrm{CO}_{2}\right)$.

In 2010, the Ministry of Energy and Petroleum, through the Kenya Power Company, commenced a pilot program to hybridize these off-grid power stations by installing renewable energy power sources, particularly wind and PV-solar.

Currently, there are off-grid diesel power stations as well as pilot hybrid systems (solar, wind or solar/wind), and new installations by the Rural Electrification Authority (REA) are currently ongoing. One of such operational stations is Habaswein, which consists of a $410 \mathrm{~kW}$ diesel generator, a $60 \mathrm{~kW}$ wind power plant and a $30 \mathrm{kWp}$ photovoltaic (PV) solar plant.

\subsection{Statement of the Problem}

The installations of off-grid hybrid systems in remote areas, promoted by the Ministry of Energy and Petroleum, were done without a proper study and optimization. No detailed analysis has been done to establish the performance, reliability and sustainability of the hybrid power stations in the Kenyan context. The Habaswein power station is one of the pilot off-grid hybrid stations, but the contribution of renewable energy is very low, since the energy is generated almost exclusively by the diesel generator. This study is thus geared towards covering this existing gap in relation to hybrid off grid power stations in Kenya, assess their sustainability and feasibility in meeting the rural electrification challenges, including optimization criteria and levels. Furthermore, it is prudent to investigate ways of ensuring grid stability from these variable renewable energy sources.

\subsection{Justification of the Study}

As the Ministry of Energy and Petroleum promotes the installation of hybrid stations in remote areas, it is fundamental to conduct an in depth technical assessment of the existing hybrid plants on their system reliability, the value for the investments and their current system performance to advise their optimization by using renewable energy resources and ensure the technical and financial sustainability. The outcome of this study will reinforce the policy making activities of implementing the hybridization program. Furthermore, this study aims at providing information about the use of 
mini-grids as a convenient solution to increase electricity access in remote areas. This information is required to provide impetus to upscale the installation of the mini-grids and hybrid systems. The study will also provide technical inputs on methods and ways of optimizing the hybrid-systems.

\subsection{Objectives}

\subsubsection{Overall Objective}

The overall objective of this research is to reinforce the policy making activities of implementing the hybridization of off-grid power stations program in Kenya and provide lessons learned on the development of mini-grids aimed at increasing access to electricity in remote areas of developing countries.

\subsubsection{Specific Objective}

The specific objective of the research is to evaluate the performance of the Habaswein off-grid hybrid power station based on wind, PV-solar and diesel generation, assess the potential of the renewable energy sources and optimize the existing systems to enhance its reliability, performance and sustainability.

\section{Literature Review}

\subsection{The Relevance of Hybrid Systems in Off-Grid Electrification Projects}

Planning for universal electricity access in countries currently with a low electrification level will entail large numbers of new grid connections. This may require the reinforcement or expansion of the transmission network and the addition of new generation, therefore demanding a complete appraisal of the power system [4], with a focus on both off-grid and on-grid markets across generation, distribution, transmission and customers.

The growing consideration towards the target of universal access to energy has emphasized the role of rural electrification, and off-grid small-scale generation represents one of the most appropriate options [5].

Hybrid stand-alone electricity generating systems are often considered more reliable and less costly than systems that rely on single source of energy [6] and those based on renewable energy are economically viable especially in remote locations $[7,8]$. During the recent years, the combined use of renewable energy sources, especially wind and solar, is becoming increasingly attractive and being widely used as an alternative to fossil fuel energy [9]. Governments therefore ought to regularly evaluate the renewable power development policies in order to effectively promote the application of renewable energy sources [10], especially for off-grid power plants, since the fuel procurement can be a serious issue in rural areas, due to lack of good infrastructure, combined with long distances existing between the mini-grid and the fuel station; however, this aspect is usually disregarded in designing the mini-grid [11].

Another important aspect of evaluation of energy systems is the Project sustainability and its impact on sustainable development, in which the energy plays a crucial role.

Most of the existing off-grid solutions, whilst having a very positive impact in delivering basic energy services, are not focused on productive uses-the main driver of job creation and economic growth. It is therefore necessary to upscale the ambition of off-grid electrification efforts. This could be helped by the ongoing trend of cost reduction and performance improvement of the technologies for electricity supply and demand, which now allow for addressing electrification in different ways [4].

The energy availability, exploitation, development and use influences practically all fields of social, economical and political activities, environment and climate and often determines whether nations will live in peace or conflict with each other. 


\subsection{Alternative Methodologies for Off Grid Electrification Projects}

Bhattacharyya reviewed alternative methodologies that are used for off-grid electrification projects to identify the features of each methodological approach and to present their strengths and weaknesses [12]. He focused on techno-economic feasibility studies, analytical works highlighting methodological applications and practice oriented literature. The review identified five methodological options, namely: worksheet-based tools, optimization tools, multi-criteria decision-making tools, system-based participatory tools and hybrid approaches. He recommended a hybrid approach that combines two or more options to take advantage of their strengths and weaknesses as well as to verify results from alternative approaches, but this can be resource intensive and will therefore require careful consideration on a case-by-case basis.

Other researchers have focused their study on social and environmental criteria, stating that they have not been fully integrated in rural electrification projects design and play often an opposing role to technical and economic criteria, and thus elaborating multi-criteria decision-making methods, such as, namely, the Analytical Hierarchy Process (AHP) and Compromise Ranking method (VIKOR), to facilitate the selection of the best solution for electrical supply of remote rural locations, involving technical, economic, environmental and social criteria [13]. A similar approach was taken by Domenech, Ferrer-Martí and Pastor, who published a hierarchical methodology based on a novel three-stage structure: Stage 1 consists of three assessments to define the target community; Stage 2 is the design process itself and groups the alternatives generation and selection phases identified in literature; and Stage 3, which is optional, allows trying to diminish the cost of the solution, maintaining the technical and social design considerations decided in the previous stage [14].

\subsection{Systems Optimization}

The optimum design of a hybrid system in rural areas is challenging due to uncertain load demand, nonlinear characteristics of renewable components, the high number of variables and parameters to be considered, and the fact that the optimum configuration and optimum control strategy of the system are interdependent [15].

This complexity is higher in the first system design than in the system optimization mainly due to error in short-term load forecasting that might be significant in isolated and rural context due to the high variability of the community consumption in the early stages of electrification and the difficulty to obtain data from the area and develop an estimation method [16]. However, there are software tools, such as LoadProGen, developed by the Polytechnic University of Milan that, given a set of input data, can simulate the corresponding load profiles which can be employed in the design process of off-grid systems for rural electrification [17].

An optimizing sizing method is necessary in order to efficiently and economically utilize the renewable energy resources. The optimizing method can help guarantee the lowest investment with full use of the technologies, so that the hybrid system can work at the optimum conditions in terms of investment and system reliability. This type of optimization requires the assessment of the system's long-term performance in order to reach the best compromise for both reliability and cost.

To select an optimum combination for a hybrid system to meet the load demand, evaluation must be carried out on the basis of power reliability and system life-cycle cost [15].

The analysis should be conducted not only on the power generation side but also considering the possibility of a storage component. In this regard, a case study of a wind power plant in Sao Vicente, Cape Verde, has showed that combining renewable energy forecasting and energy storage is a promising solution which enhances diesel fuel savings as well as enables the isolated grid to further increase the annual renewable energy penetration from the current $30.4 \%$ up to $38.0 \%$ while reducing grid unreliability. In general, since renewable energy forecasting ensures more accurate scheduling and energy storage can compensate the missing or exceeding scheduled production, this solution is applicable to any small size isolated power grid with large renewable energy penetration [18]. 
However, the design, optimization and operation control of hybrid energy systems with two or more energy sources are complex and the risk of failure is increased [19]. Researchers have studied a wide variety of methods to reduce the complexity of designing hybrid energy systems. Some useful methods include Probabilistic, Analytical, Iterative and Hybrid methods [20]. Several studies have used these methods to design optimal hybrid systems combining two or more energy sources.

In fact, an overview of the latest research developments concerning to the use of optimization algorithms for design, planning and control problems in the field of renewable and sustainable energy has showed that the number of research papers that use optimization methods to solve renewable energy problems has increased dramatically in recent years, especially for wind and solar energy systems. Some of these optimization methods are based on traditional approaches, such as mixed-integer and interval linear-programming, Lagrangian relaxation, quadratic programming and Nelder-Mead Simplex search, while a growing number of research papers tackle these problems using heuristic optimization methods, especially genetic algorithms and particle swarm optimization [21].

In conclusion, the techno-economic analysis of the hybrid system is essential for the efficient utilization of renewable energy resources. Due to multiple generation systems, hybrid system analysis, is quite complex and requires to be analyzed thoroughly. This requires software tools for the design, analysis, optimization, and economic viability of the systems [22]. By using simulation and modeling programs, the optimum configuration can be found by comparing the performance and the energy production cost of different system configurations.

For instance, a feasibility study of a small hydro-PV-wind hybrid system for rural electrification in Dejen District, in Ethiopia, proposed the optimal hybrid combination of wind, hydro, diesel, battery systems by using HOMER software 3.10.1 [23].

Another example is given by the design of a microhydro-PV hybrid system by using HOMER software: thanks to the yearly simulation of the system operation, making it possible to analyze the complementary contributions of both components, the necessity of storing energy and introducing a diesel generator as back-up was revealed [24].

A further study was conducted on off-grid electrification of seven villages in the Almora district of Uttarakhand State, India, where biomass, solar, micro-hydro and wind energy sources were considered and analyzed using LINGO and HOMER software packages. The scenario accounting $44.99 \%$ of energy produced by micro-hydro, $30.07 \%$ by biomass, $5.19 \%$ by biogas and $4.16 \%$ by PV, along with the additional resources of wind (1.27\%) and energy plantation (12.33\%) has been found to be the best among the different options considered [25].

Furthermore, Connolly et al. [26] did a comparative study of 68 computer tools for integration of renewable resource in various energy systems. Accordingly, HOMER was evaluated as one of the most applicable for optimization, feasibility and sensitivity analysis of both off-grid and grid connected micro power systems. Akikur et al. [19] also pointed out that HOMER is the most used and best known of all the software tools so far developed, as it is explained below.

\subsection{Resource Potential}

Kenya is endowed with vast indigenous renewable energy resource potential, as confirmed by various studies. In 2001, the Ministry of Energy and Petroleum developed a Wind and Solar Resources Atlas, using synoptic weather data, which was improved in 2008 in collaboration with UNDP and other partners, with higher resolution. It showed that wind regimes can support commercial electricity generation with average speeds ranging 8-14 m/s in certain parts of Kenya, such as Marsabit, Turkana, Ngong and the Coastal region, representing a total area of 22,000 $\mathrm{km}^{2}$. Buoyed by this positive outcome, the Ministry of Energy and Petroleum commenced wind data logging in specific high potential areas in December 2009. In 2013, these data were analyzed, leading to higher resolution wind maps that confirmed the huge potential for wind energy development. Incidentally, the areas with adequate wind resources are in the remote areas on northern Kenya, which are not served by grid connected electricity. 


\section{Materials and Methods}

\subsection{Study Location}

The study has been undertaken at Habaswein hybrid off grid power station situated in Kenya, its geographical coordinates are $1^{\circ} 0^{\prime} 33^{\prime \prime}$ North, 39 $29^{\prime} 17^{\prime \prime}$ East. Habaswein is a settlement in Kenya's northeastern region (Figure 1), which is almost exclusively inhabited by ethnic Somalis. The name Habaswein literally means a lot of dust. The town falls under Wajir south constituency in Wajir County whose population was 138,000 in the 2009 census.

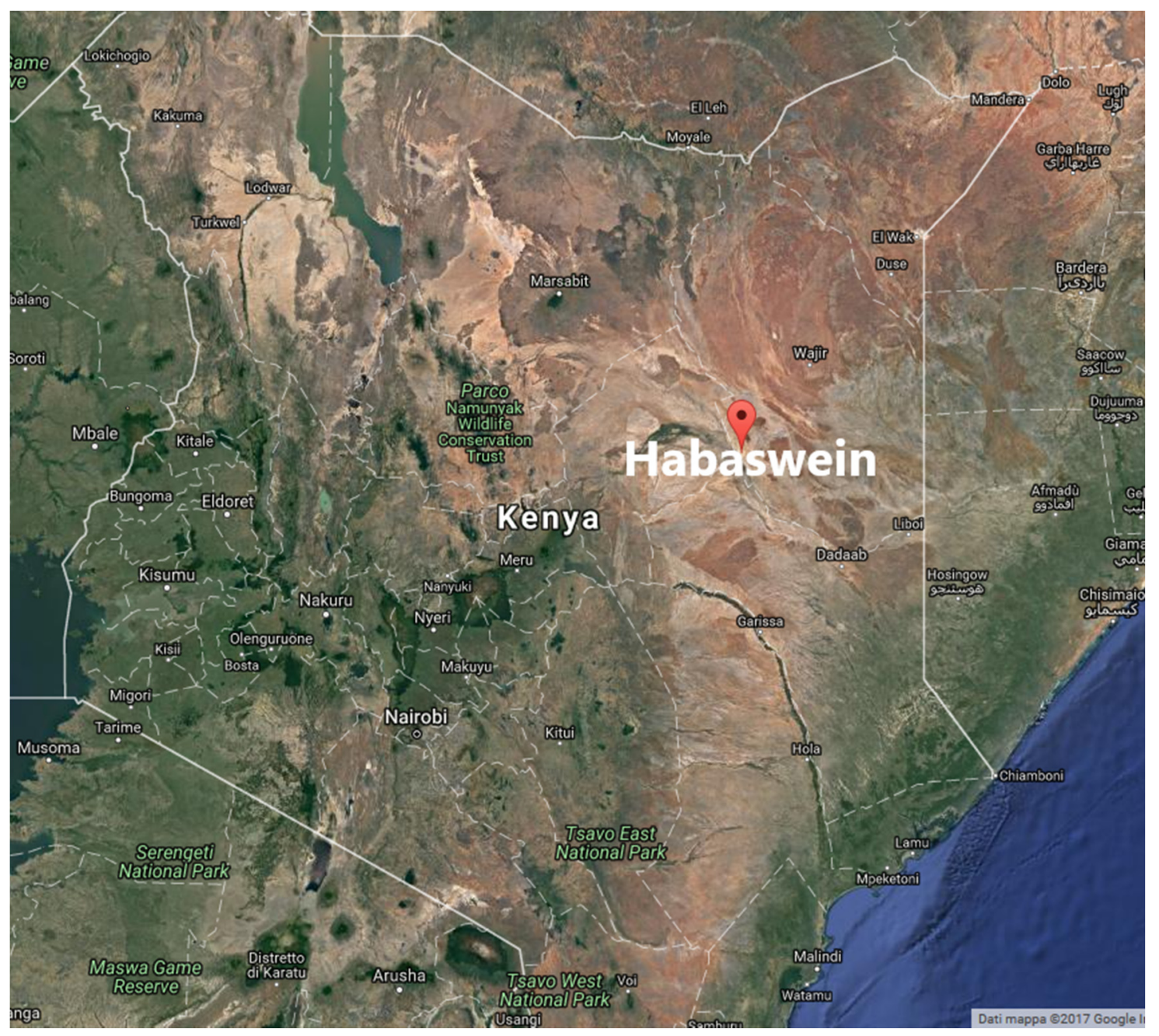

Figure 1. Habaswein location.

\subsection{Data Collection}

Raw primary data of the hybrid station performance for five years have been obtained from the Kenya Power and Lighting Company (KPLC) in regards to the energy generated by the diesel, wind and solar components, the fuel consumption, and the power loads.

\subsection{Mini-Grid Technical Specification}

The existing electricity generation is a diesel-based system. The system consists of one diesel generator with total capacity of $410 \mathrm{~kW}$, a $30 \mathrm{kWp}$ photovoltaic plant and a wind farm of three wind turbines of $20 \mathrm{~kW}$ each, all synchronized in the same bus bar. The system supplies electricity demand 
for nearly 365 days a year. A diesel generator was installed in 2010 and, due to serious problems, it was substituted in 2012 by a similar generator with the same power.

\subsection{Data Analysis}

\subsubsection{Market Growth and Energy Production}

In five years of operation of the mini-grid, the number of customers has almost tripled; in parallel with the number of customers with a growth from 700 customers to almost 1800.

In parallel there is also a growth of the requested load. The energy production growth rate is less than the customer's growth probably because the new customers are domestic users, while the first customers were both domestic and productive users.

The increase of energy production is about $50 \%$ in four years. It can also be noticed that this production increment was realized exclusively through the diesel generator; Energy production through renewable sources remains marginal.

\subsubsection{4-Yearly Analysis}

The behavior of the Habaswein Hybrid mini-grid is presented in more detail by choosing a reference year (2014), and by carrying out a global annual, monthly and daily analysis. The year 2014 was chosen because there were fewer interruptions of the mini-grid operation.

Energy production has been realized almost entirely using Diesel generators. Only $5 \%$ of the electricity generation was produced using renewable energy sources.

Monthly energy production presents a limited variability over the year with an average energy value of $91,417 \pm 7671 \mathrm{kWh}$ with a total yearly production of $1,097,413 \mathrm{kWh}$. Referring to the mean value, the maximum and minimum of the energy production deviates by $10 \%$.

Studying the typical behavior of the energy production during a day, can be noticed two peaks in the production, one towards the middle of the day and one evening.

\subsubsection{Operational Costs}

In 2014 , the total amount of the operational cost was $\$ 578,681.82$, including diesel supply, ordinary and extraordinary maintenance.

Table 1 shows the monthly operational data of 2014, from this data can be calculated the average energy cost of energy which is $0.46 \$ / \mathrm{kWh}$ but there is a strong variation during the year with a maximum variation of $0.10 \$ / \mathrm{kWh}$, corresponding to $22 \%$ of the energy price.

This important variation is due to the diesel price variability and to operation condition of the plant, the Figure 2 compares the Energy production rate with the diesel generator efficiency, it is evident that the two curves have opposite trend, when the Energy production rate increases the energy cost decreases and vice-versa.

This shows how strong is the influence of the diesel generator on the variation of the operational cost of the mini-grid of Habaswein and how uncertainty there is around the energy cost variation. 
Table 1. Monthly operational data, year 2014.

\begin{tabular}{|c|c|c|c|c|c|c|c|c|c|c|c|c|}
\hline \multirow{2}{*}{$\begin{array}{l}\text { Operational Data } \\
\text { Consumption (L) }\end{array}$} & \multirow{2}{*}{$\begin{array}{c}\text { January } \\
35,742\end{array}$} & \multirow{2}{*}{$\begin{array}{c}\text { February } \\
31,359\end{array}$} & \multirow{2}{*}{$\begin{array}{l}\text { March } \\
35,044\end{array}$} & \multirow{2}{*}{$\begin{array}{l}\text { April } \\
29,888\end{array}$} & \multirow{2}{*}{\begin{tabular}{c|} 
May \\
28,796
\end{tabular}} & \multirow{2}{*}{$\begin{array}{c}\text { June } \\
32,879\end{array}$} & \multirow{2}{*}{$\begin{array}{c}\text { July } \\
33,678\end{array}$} & \multirow{2}{*}{$\begin{array}{c}\text { August } \\
35,758\end{array}$} & \multicolumn{2}{|c|}{ September October } & \multicolumn{2}{|c|}{ November December } \\
\hline & & & & & & & & & 33,507 & 36,047 & 30,437 & 28,150 \\
\hline Cost (\$) & 46,360 & 41,318 & 46,292 & 39,481 & 38,069 & 44,155 & 45,216 & 47,809 & 37,834 & 47,705 & 37,672 & 31,292 \\
\hline Energy Production (kWh) & 92,868 & 89,808 & 83,127 & 81,364 & 95,920 & 85,016 & 103,992 & 94,028 & 96,433 & 103,216 & 89,040 & 82,604 \\
\hline Energy cost $(\$ / k W h)$ & 0.50 & 0.46 & 0.56 & 0.49 & 0.40 & 0.52 & 0.43 & 0.51 & 0.39 & 0.46 & 0.42 & 0.38 \\
\hline $\begin{array}{l}\text { Energy production Rate } \\
(\mathrm{kWh} / \mathrm{L})\end{array}$ & 2.60 & 2.86 & 2.37 & 2.72 & 3.33 & 2.59 & 3.09 & 2.63 & 2.88 & 2.86 & 2.93 & 2.93 \\
\hline
\end{tabular}

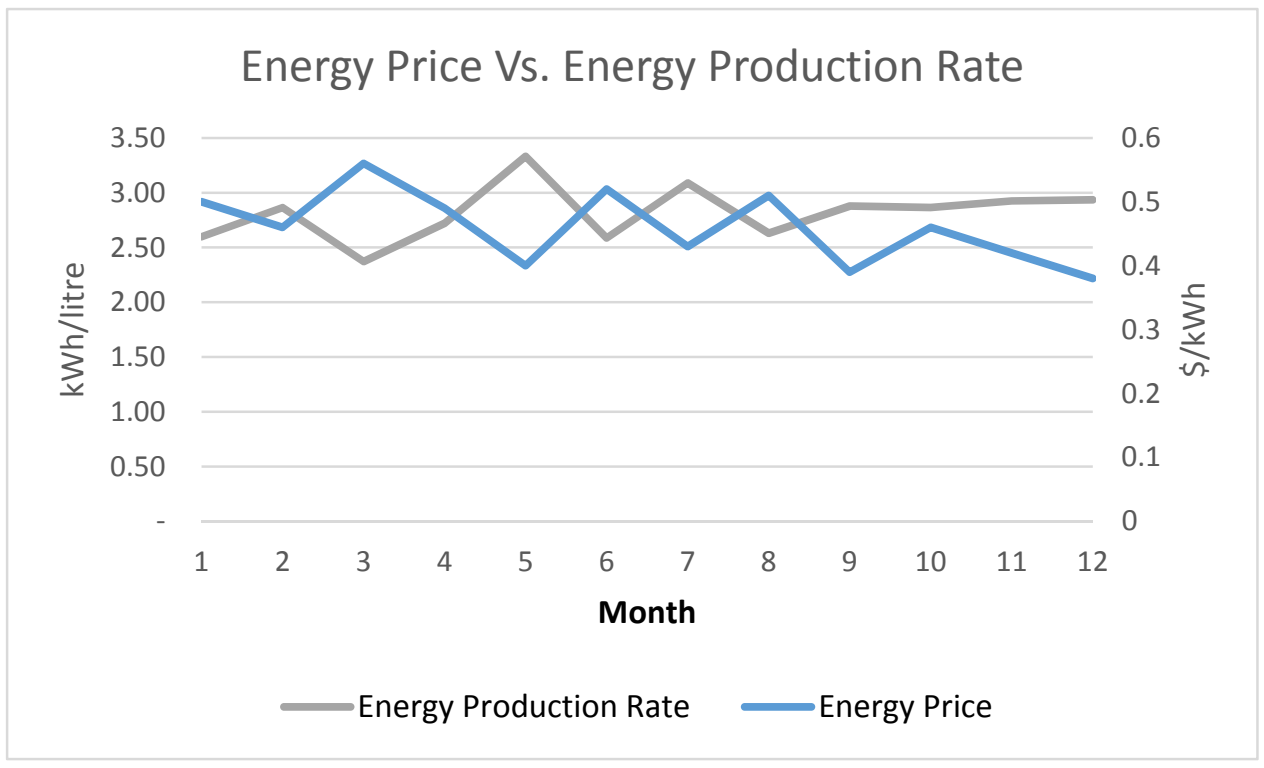

Figure 2. Energy price vs. energy production rate. 


\subsection{Simulation and Optimization with HOMER PRO}

HOMER software will be used to simulate and model different mix scenarios with the aim of establishing the optimal penetration levels of renewable energy. HOMER is a computer model that simplifies the task of evaluating design options for both off-grid and grid-connected power systems for remote, stand-alone and distributed generation applications. It has been developed by United States National Renewable Energy Laboratory since 1993. It is developed specifically to meet the needs of renewable energy industry's system analysis and optimization. There are three main tasks that can be performed by HOMER: simulation, optimization and sensitivity analysis. In the simulation process, HOMER models a system and determines its technical feasibility and life cycle. In the optimization process, HOMER performs simulation on different system configurations to come out with the optimal selection. In the sensitivity analysis process, HOMER performs multiple optimizations under a range of inputs to account for uncertainty in the model inputs. Detailed description on HOMER software can be found in $[27,28]$.

HOMER Pro Microgrid Analysis Tool 3.9.2 [29] is the simulation tool adopted for the optimization of the plant. This simulation tool assists in the planning and design of renewable energy based micro-grid. The physical behavior of each power plant configuration, their life-cycle (excluding dismantling) cost and the energetic and economic comparison were made using the three main operations of the software: Simulation, Optimization and Sensitivity Analysis.

In the Simulation area, HOMER Pro determines technical behavior, feasibility and life-cycle cost of a system for every hour of the year. The assessment is made not only for the entire system: the operation of each component is simulated to examine how the components works in relationship with the entire system.

In the Optimization section HOMER displays each feasible system and its configuration in a search space sorted by the minimum cost depending on the total net present cost. In this way, we can find the optimal configuration which satisfies the constraints imposed in the model. The description of economic output is set out in the following paragraph.

In the section of Sensitivity Analysis, the user can analyze the effects of parameter variations in time and the behavior of the sensitivity variables. The sensitivity variables are those parameters entered by the user and having different values.

Before the construction of the model, the first step needed is the evaluation of the load, which could be electric, thermal or both, although in this study we focus on the electric load. In the present paper, the yearly electric load profile adopted was the measured load of 2014 with 30-min step.

\subsection{The Hybrid Optimization Model and Problem Formulation}

The configuration of the system is studied when designing a power system in terms of the components, and size, selecting from numerous technology options and various energy resources.

The HOMER was developed by the U.S. National Renewable Energy Laboratory to simplify the task of designing multisources power systems and evaluating the maximum number of possible system configurations [28]. The optimal system with the lowest net present cost (NPC) is determined using this micropower optimization model.

The total annualized cost $\left(C_{a n n \_t o t}\right)$ represents the annual cost of the project in (\$/year), which includes the initial costs $\left(C_{\text {capann }}\right)$, replacement costs $\left(C_{\text {repann }}\right)$, and $\mathrm{O} \& \mathrm{M}$ costs $\left(C_{O \& M a n n}\right)$, and is expressed mathematically as:

$$
C_{\text {ann_tot }}=C_{\text {capann }}+C_{\text {repann }}+C_{O \& M a n n} \text {. }
$$

On the other hand, total annualized cost can be defined as the annualized value of the total net present cost, and is expressed mathematically as:

$$
C_{\text {ann_tot }}=C_{N P C} \times \operatorname{CRF}(i, N) \text {. }
$$


The capital recovery factor $(C R F)$ converts a net present cost $\left(C_{N P C}\right)$ into a flow of equal annual payments over a specified time, and calculates this value based on the annual interest rate (i) and number of years $(N)$, and is expressed mathematically as:

$$
C R F(i, N)=i(1+i)_{N}(1+i)_{N}-1
$$

The $C_{N P C}$ represents all the costs that occur within the project lifecycle, with future cash flows discounted to the present using the discount rate. NPC includes the initial costs (IC), replacement costs, and $\mathrm{O} \& \mathrm{M}$ costs. Besides, salvage value that occurs at the end of the project lifetime that reduces the total NPC. The salvage value $(S)$ is the value remaining for each component after a project's lifetime is completed and is computed using:

$$
S=C_{\text {rep }} R_{\text {rem }} R_{\text {comp }},
$$

where $R_{\text {comp }}$ is the lifetime of the component (years), $R_{\text {rem }}$ is the remaining lifetime of the component (years), and $C_{\text {rep }}$ is the replacement cost of the component (\$).

The NPC objective function for system optimization based on Equation (2) is:

$$
\operatorname{minimize}\left(C_{N P C}=C_{\text {ann_tot }} C R F(i, N)\right),
$$

which is subject to:

$$
\begin{gathered}
0<\mathrm{E}_{\mathrm{PV}}, \\
\mathrm{E}_{\text {annual-demand }}<\mathrm{E}_{\mathrm{PV}}, \\
\mathrm{E}_{\text {Battery }}+\mathrm{E}_{\mathrm{PV}}=\mathrm{E}_{\mathrm{BS}}+\mathrm{E}_{\text {Losses }} .
\end{gathered}
$$

(i) The energy output of the PV array $\left(\mathrm{E}_{\mathrm{PV}}\right)$ must always be positive, as given in Equation (6), and must be at least $10 \%$ of the total annual demand ( $\left.E_{\text {annual-demand }}\right)$. The factors influencing the solar energy generation are the peak capacity of the $\mathrm{PV}$ array $\left(\mathrm{Y}_{\mathrm{PV}}\right)$ in $\mathrm{kW}$, the peak solar hour (PSH) in hours, and PV efficiency, which represents the relationship between the target yields $\left(f_{\mathrm{PV}}\right)$ and the actual target. The mathematical modeling in HOMER calculates the total annual energy contribution of the solar array [28] and is expressed as:

$$
\mathrm{E}_{\mathrm{PV}}=\mathrm{Y}_{\mathrm{PV}} \times \mathrm{PSH} \times \mathrm{f}_{\mathrm{PV}} \times 365 \text { day } / \text { year. }
$$

(ii) To ensure a balance between demand and production power, the energy production of the sources (PV array and battery $\left.\left(\mathrm{E}_{\text {Battery }}\right)\right)$ should cover the needs of the $\mathrm{BS}\left(\mathrm{E}_{\mathrm{BS}}\right)$ plus the losses $\left(\mathrm{E}_{\text {Losses }}\right)$ incurred by a DC-DC regulator, inverter, and active cooling.

The discharging and charging limits of a battery depend on its power rating and vary between the values $\left(\mathrm{P}_{\min }, \mathrm{P}_{\max }\right)$, where $\mathrm{P}_{\min }$ is the minimum state of charge and $\mathrm{P}_{\max }$ is the maximum state of charge of the battery, which is also the nominal capacity of the battery bank. Moreover, the DOD, efficiency, days of autonomy $\left(A_{B}\right)$, and lifetime of the battery $\left(L_{B}\right)$ are important, as they significantly affect the system's total cost. The $D O D$ refers to the maximum energy delivered from the battery and is defined using equation [28]:

$$
D O D=1-S O C_{\min } 100,
$$

where $S O C_{\min }$ is the lower limit provided in the battery datasheet so that the battery does not discharge below the minimum state of charge.

In the case of a PV array malfunction, the battery bank feeds the required energy load. Thus, the battery bank autonomy $\left(\mathrm{B}_{\text {aut }}\right)$ is a critical factor representing the potential number of days that the battery bank can supply the required energy load without any PV array contribution. This value is expressed as the ratio of the battery bank size to the BS load [28]:

$$
A_{B}=N_{b a t} \times B_{V} \times B_{Q} \times B_{D O D} \times(24 \mathrm{~h} / \mathrm{d}) L_{B S} .
$$


where $B_{V}$ is the nominal voltage of a single battery in $V, N_{b a t}$ is the number of batteries in the battery bank, $L_{B S}$ is the average daily $B_{S}$ load in $\mathrm{kWh}$, and $B_{Q}$ is the nominal capacity of a single battery in Ah.

Using HOMER, the battery lifecycle is calculated [28] based on:

$$
L_{B}=\min \left(N_{\text {bat }} \times Q_{\text {lifetime }} Q_{\text {thrpt }}, R_{\text {batt }, f}\right) .
$$

where $R_{\text {batt }, \text { is }}$ is the battery float life in years, $Q_{\text {thrpt }}$ is the annual battery throughput in $\mathrm{kWh}$, and $Q_{\text {lifetime }}$ is the lifetime throughput of a single battery in $\mathrm{kWh}$.

The number of batteries in series is equal to the DC bus-bar voltage $\left(V_{b-b}\right)$ divided by the voltage rating $\left(B_{V}\right)$ of one of the batteries selected:

$$
N_{\text {seriesbatt }}=V_{b-b} B_{V} .
$$

The number of parallel paths is obtained by dividing the total number of batteries by the number of batteries connected in series.

Figure 3 summarizes the optimization methodology to identify the optimal solar system with the lowest NPC [30].

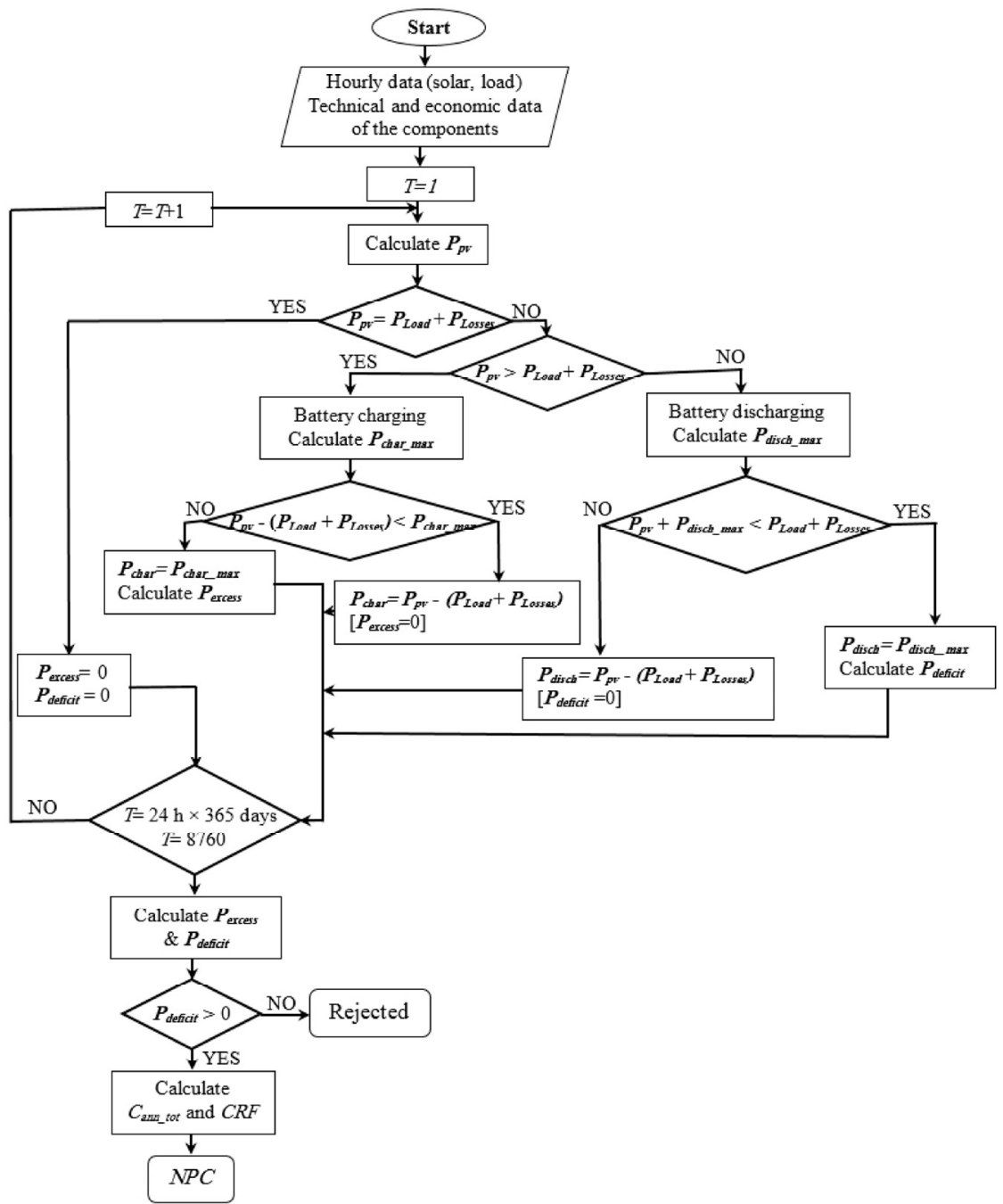

Figure 3. Flowchart of the optimization process for solar powered system.

HOMER initiates the hourly simulation of every possible configuration, uses the $\mathrm{PV}$ array $\left(\mathrm{P}_{\mathrm{PV}}\right)$ to compute the available power, compares it with the electric load $\left(\mathrm{P}_{\text {Load }}\right)$ and losses $\left(\mathrm{P}_{\text {Losses }}\right)$, and finally 
decides how the additional power should be generated during deficits (battery discharging) or how the surplus power should be managed in times of excess (battery charging).

\subsection{Renewable Resources Assessment}

We have considered two possibly available renewable resources, solar irradiation and wind. The solar irradiation and surface annual solar radiation data have been obtained from an average of 20 years of NASA data, which interpolate data of available weather stations to infer specific location (freely available also at [31]). The scaled average annual of daily solar radiation in this region is $5.90 \mathrm{kWh} / \mathrm{m}^{2}$. The average clearness index is 0.59. Based on these data, we show the assumed values for the different months in Figure 4.

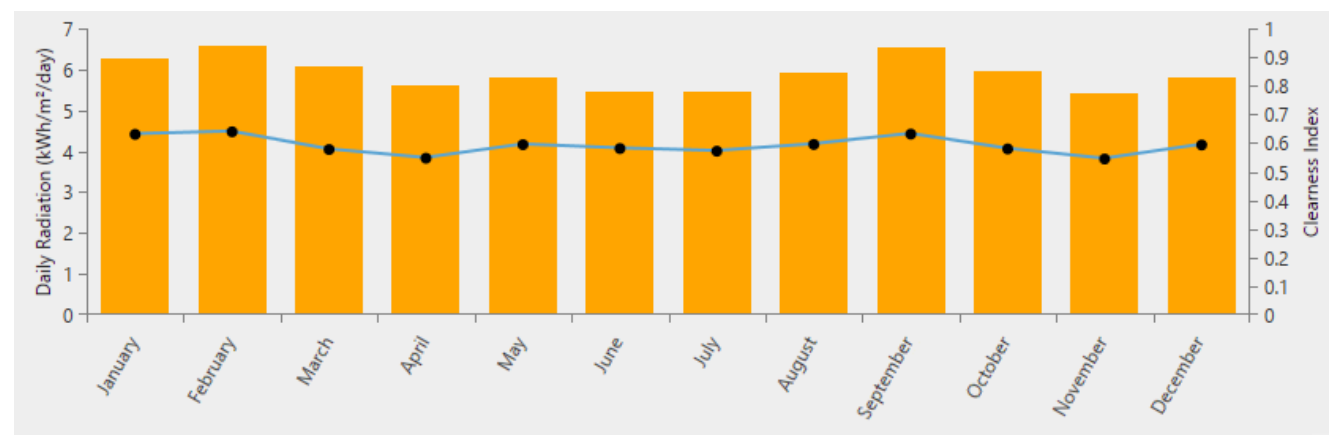

Figure 4. Assumed average daily solar irradiation and clearness index for the plant location.

Implementation of the wind solution was discarded because the data analysis revealed a low energy production of the existing turbines. Indeed, the NASA wind data and preliminary on-site wind measurement do not justify the measured low energy production; the reason this is not working should be investigated. The biomass option was not considered due to their local scarcity and to the well-known problems related to deforestation, crop energy competition with food production, and relatively high operational costs of such plants.

\subsection{Components and Cost}

The PV array size is calculated using the Homer Optimizer ${ }^{\mathrm{TM}}$ algorithm. The considered PV system and replacement cost is $2200 \$ / \mathrm{kWp}$. The $\mathrm{O} \& \mathrm{M}$ cost is set to $10 \$ / \mathrm{kWp} /$ year. The solar module type is a polycrystalline PV panel with efficiency $15 \%$. The costs include purchase, transportation and installation of modules, all balance of system components like cables and structures (excluding the inverter) and the security system.

The Inverter size is calculated using the Homer Optimizer ${ }^{\mathrm{TM}}$ algorithm. The cost is set to be $300 \$ / \mathrm{kW}$, and the efficiency of the inverter is assumed to be $95 \%$.

For the battery energy storage systems (BESS) we consider a Li-Ion battery, with round trip losses of $8 \%$ [32], an estimated cost of $600 \$ / \mathrm{kWh}$, an O \& M cost of $10 \$ / \mathrm{kWh} /$ year, and a connection on the DC bus. For the limited BESS solution, the size of the BESS is varied from $500 \mathrm{kWh}$ to $1300 \mathrm{kWh}$ with a step of $50 \mathrm{kWh}$.

The diesel Generator is considered as a back-up component. The present micro-grid has a $410 \mathrm{~kW}$ generator but, most of the time, it is oversized compared to the load curve because the maximum requested power is $292 \mathrm{~kW}$ and the average requested power is $122 \mathrm{~kW}$.

The minimum load ratio considered suitable for the generator is $25 \%$, i.e., $102.5 \mathrm{~kW}$. With requested load under this limit the generator works at low efficiency. Furthermore, in case of high renewable energy penetration, the generator works as a backup system, this means that it could be used to supply also little amount of power, i.e., when the BESS or the PV need an integration to reach a too high load, in this case the number of starts of the diesel generator is high. Thus, it has been evaluated the 
opportunity of installing adjunctive little generators to answer the little load requested by the system and to avoid that the $410 \mathrm{~kW}$ generator works at low efficiency.

For the $410 \mathrm{~kW}$ diesel generator it has not considered a capital cost because it is actually working, the replacement cost is $\$ 90,000$, the $\mathrm{O} \& \mathrm{M}$ cost is $2 \$ / \mathrm{h}$. The $100 \mathrm{~kW}$ generator cost and its replacement are set to $\$ 40,000$ and the $O \& M$ cost is $2 \$ / \mathrm{h}$. The $50 \mathrm{~kW}$ generator cost and its replacement are set to $\$ 25,000$ and the $\mathrm{O} \& \mathrm{M}$ cost is $1 \$ / \mathrm{h}$. The diesel cost is set to $1.28 \$ / \mathrm{L}$ which is the average cost of the diesel in Habaswein in 2014.

The lifetime of the plant, used in the economic evaluation is 25 years. The main factors to evaluate the economic optimal solution for the optimization of the Habaswein power plant are Net Present Cost (NPC) and the cost of electricity (COE). The assumed lifetimes of the PV panels, inverter and BESS are, respectively: 25 years, 15 years, 10 years, and $15,000 \mathrm{~h}$. The discount rate of this study is set to $10 \%$ [33] and the inflation rate is assumed to be $8 \%$ [34].

\section{Results}

The study evaluates three possible solutions, with and without BESS, the results of the different solutions are summarized in Table 2.

The first solution evaluated was a Hybrid system without BESS (Figure 5), the absence of a BESS implies the excess energy produced by the power plant cannot be stored and be available anytime, so the diesel generators will satisfy the demand when the PV system is not producing enough energy.

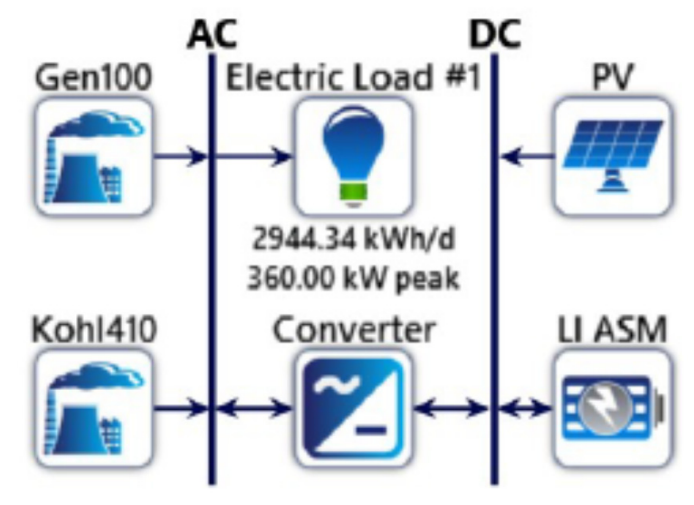

Figure 5. Scheme of the hybrid system without BESS (Battery Energy Storage System) solution.

In this case, the optimal configuration is formed by a $569 \mathrm{kWp}$ PV generator, with a $193 \mathrm{~kW}$ inverter, and two diesel generators of $100 \mathrm{~kW}$ and $410 \mathrm{~kW}$.

The PV total energy production would be $868,391 \mathrm{kWh} /$ year and satisfies about $40 \%$ of load energy consumption. The excess energy produced by the PV plant is $430,993 \mathrm{kWh}$, so almost $50 \%$ of the energy produced is not consumed.

The installation of an additional $100 \mathrm{~kW}$ diesel generator allows covering the base load. In this way, the $410 \mathrm{~kW}$ diesel generator would be switched on only in the case of high consumption, thus avoiding conditions of very low loads ( $<25 \%$ of nominal capacity): this solution improves the global efficiency of the power generation with fossil fuels and the diesel generators total production is $637,798 \mathrm{kWh} /$ year with a fuel consumption of $206,748 \mathrm{~L} /$ year.

In this optimization scenario, the excess electricity generated by PV is $408,305 \mathrm{kWh} /$ year, corresponding to $27.1 \%$ of the total electricity generation (1,506,189 $\mathrm{kWh} /$ year). This excess cannot be used due to the lack of energy storage.

With a COE of $0.354 \$ / \mathrm{kWh}$ and a NPC of $\$ 7,568,600.45$, this optimization scenario, compared to the current situation, reduces: (i) the diesel consumption by $184,537 \mathrm{~L} /$ year; (ii) the $\mathrm{CO}_{2}$ emissions by $484,649 \mathrm{~kg} /$ year; and (iii) the emissions of other pollutants by $3612 \mathrm{~kg} /$ year.

The second solution evaluated was a Hybrid diesel/PV system with limited BESS (Figure 6). 
The BESS allows the possibility to store the excess energy produced by the power plant. In such scenario, the diesel generators will support the system to satisfy the demand when the PV system and the BESS cannot supply enough energy. In this first simulation, we considered a limited BESS capacity to stay within a battery capital cost of $\$ 800,000$.

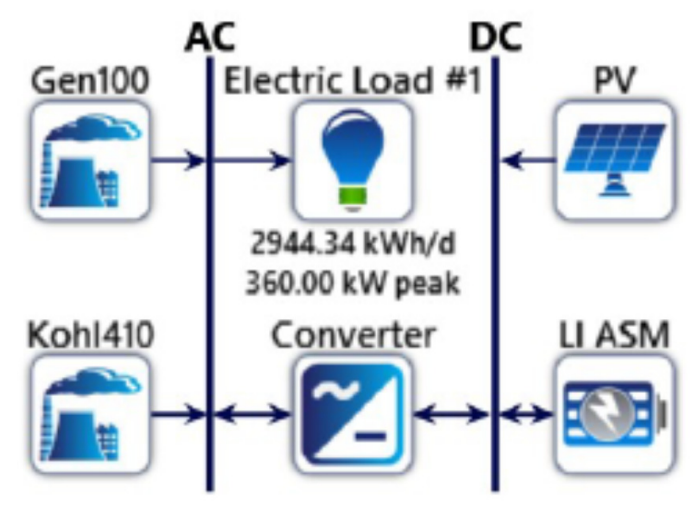

Figure 6. Scheme of the hybrid system with limited BESS solution.

The optimal configuration is formed in this case by a $578 \mathrm{kWp} \mathrm{PV} \mathrm{generator,} \mathrm{with} \mathrm{a} 206 \mathrm{~kW}$ inverter, a $1328 \mathrm{kWh}$ BESS capacity, and two diesel generators of $100 \mathrm{~kW}$ and $410 \mathrm{~kW}$. The diesel generators total production is $339,665 \mathrm{kWh} /$ year with a fuel consumption of $109,927 \mathrm{~L} /$ year.

PV total energy production is $882,471 \mathrm{kWh} /$ year and satisfies $68.4 \%$ of the load energy consumption, thanks also to the energy stored in the BESS. There is still an excess of energy produced by the PV plant, corresponding to the cases when BESS are already fully charged and the production exceeds the consumption (usually, during the afternoon). Such excess is $82,071 \mathrm{kWh} /$ year, corresponding to $6.7 \%$ of the total electricity generation which is $1,222,136 \mathrm{kWh} /$ year. Compared to the previous BESS-less case, this implies a better exploitation of the solar resource.

With a COE of $0.305 \$ / \mathrm{kWh}$ and a NPC of $\$ 6,507,321.53$ this optimization scenario, compared to the current situation, reduces: (i) the diesel consumption by $281,358 \mathrm{~L} /$ year; (ii) the $\mathrm{CO}_{2}$ emissions by $738,656 \mathrm{~kg} /$ year; and (iii) the emissions of other pollutants by $5681 \mathrm{~kg} /$ year. Compared to the first case (no BESS), the diesel consumption is reduced by almost a half.

The third solution evaluated was a Hybrid diesel/PV system with optimized BESS (Figure 7).

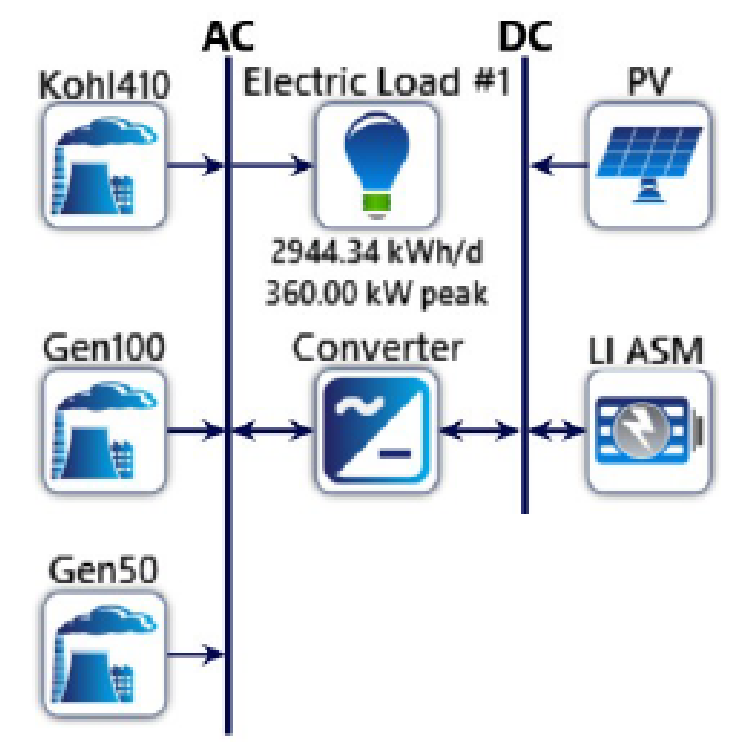

Figure 7. Scheme of the hybrid system with limited BESS solution. 
We then consider a case with BESS endowed with larger capacity, exploring more expensive configurations. The optimization of the BESS has the aim to reduce the COE and the NPC of the plant to make the solution with the most affordable energy price.

In this case, the optimal configuration is formed by an $808 \mathrm{kWp}$ PV generator, with a $202 \mathrm{~kW}$ inverter, a $2598 \mathrm{kWh}$ BESS capacity and three diesel generators of $50 \mathrm{~kW}, 100 \mathrm{~kW}$ and $410 \mathrm{~kW}$. Three diesel generators have been chosen to reduce as much as possible the use of the $410 \mathrm{~kW}$ generator, which is installed as backup component. The diesel generators total production is $94,383 \mathrm{kWh} /$ year with a fuel consumption is greatly reduced to only $28,719 \mathrm{~L} /$ year.

PV total energy production is $1,233,580 \mathrm{kWh}$ /year and satisfies, thanks to the energy collected in the BESS, $91.2 \%$ of load energy consumption. In this optimization scenario, the excess electricity generated by the PV is $156,674 \mathrm{kWh}$ /year, corresponding to $11.8 \%$ of the total electricity actually distributed by the PV + BESS + diesel system $(1,327,963 \mathrm{kWh} /$ year). This excess is in proportional higher than the limited BESS solution due to the much larger PV nominal power. An exploitation of this excess would imply a larger BESS, which is economically not convenient due to the installation costs.

With a COE of $0.253 \$ / \mathrm{kWh}$ and a NPC of $\$ 6,179,443.19$, this optimization scenario, compared to the current situation, reduces: (i) the diesel consumption by $362,566 \mathrm{~L} /$ year; (ii) the $\mathrm{CO}_{2}$ emissions by $951,658 \mathrm{~kg} /$ year; and (iii) the emissions of other pollutants by $7310 \mathrm{~kg} /$ year.

\subsection{Environmental Evaluation}

For environmental evaluation of all solutions presented above, yearly pollutant and greenhouse gas (GHG) emissions in the operational phase were considered (Table 3). Given the intrinsic difficulties and lack of data, we do not consider the environmental impact throughout all the life cycle (cradle to grave) of the power plant, thus neglecting GHG emissions related with manufacturing, transportation, construction and dismantling. For similar reasons related to the intrinsic difficulty of a proper evaluation, we do not evaluate the impacts and costs on health and environment caused locally by the local pollutants, even though they should not be underestimated.

With these limitations, we prove the obvious result that, during the operational phase, the hybrid plants present lower emissions because fuel consumption is lower than the present plant, and the installation of a BESS achieve the maximum reduction of pollutants because the battery system can supply energy when the PV plant is not working; indeed, in the configuration without BESS, the diesel generators will work every time the PV plant is not producing enough power. Emissions are evaluated through software emissions factors (emissions per energy produced).

\subsection{Economic Evaluation}

The summary of the technical optimized solutions and their economic evaluation is shown in Table 4. The present configuration, as expressed in Section 3.3, consists of one diesel generator with total capacity of $410 \mathrm{~kW}$, a $30 \mathrm{kWp}$ photovoltaic plant and a wind farm of three wind turbines of $20 \mathrm{~kW}$ each, all synchronized in the same bus bar. 
Table 2. Technical details of the proposed solutions.

\begin{tabular}{|c|c|c|c|c|c|c|c|c|}
\hline Solutions & Diesel Gen (kW) & $\begin{array}{c}\text { Numbers of Starts } \\
\text { (starts/year) }\end{array}$ & $\begin{array}{l}\text { Electrical Production } \\
(\mathrm{kWh} / \text { year })\end{array}$ & $\begin{array}{l}\text { Fuel Consumption } \\
\text { (L/year) }\end{array}$ & PV (kWp) & $\begin{array}{l}\text { PV Energy Production } \\
\text { (kWh/year) }\end{array}$ & BESS (kWh) & $\begin{array}{l}\text { BESS Energy } \\
\text { Out (kWh/year) }\end{array}$ \\
\hline Present & 410 & n.a. & $1,042,885$ & 391,285 & 30 & 38,012 & - & - \\
\hline No BESS & 410 & 602 & 495,937 & 163,241 & 569 & 863,391 & - & - \\
\hline Total & $\begin{array}{c}100 \\
-\end{array}$ & $\begin{array}{c}975 \\
1577\end{array}$ & $\begin{array}{l}141,861 \\
637,798\end{array}$ & $\begin{array}{c}43,507 \\
206,748\end{array}$ & 569 & 863,391 & - & - \\
\hline Limited BESS & $\begin{array}{l}410 \\
100\end{array}$ & $\begin{array}{l}488 \\
840\end{array}$ & $\begin{array}{l}224,775 \\
114,890\end{array}$ & $\begin{array}{l}75,030 \\
34,897\end{array}$ & 578 & 882,471 & 1328 & 292,867 \\
\hline Total & - & 1328 & 339,665 & 109,927 & 578 & 882,471 & 1328 & 292,867 \\
\hline Optim. BESS & $\begin{array}{c}410 \\
100 \\
50\end{array}$ & $\begin{array}{c}42 \\
162 \\
349\end{array}$ & $\begin{array}{l}17,179 \\
65,316 \\
11,888\end{array}$ & $\begin{array}{c}5329 \\
18,810 \\
4580\end{array}$ & 808 & $1,233,580$ & 2598 & 510,602 \\
\hline Total & - & 553 & 94,383 & 28,719 & 808 & $1,233,580$ & 2598 & 510,602 \\
\hline
\end{tabular}

Table 3. Greenhouse gas emission comparison.

\begin{tabular}{|c|c|c|c|c|c|c|}
\hline Solutions & Diesel Consumption (L/year) & $\mathrm{CO}_{2}$ Emissions (kg/year) & Other Pollutants (kg/year) & $\begin{array}{l}\text { Reduction of Diesel } \\
\text { Consumption (L/year) }\end{array}$ & $\begin{array}{c}\text { Reduction of } \mathrm{CO}_{2} \\
\text { Emissions (kg/year) }\end{array}$ & $\begin{array}{l}\text { Reduction of Other } \\
\text { Pollutants (kg/year) }\end{array}$ \\
\hline Present & 391,285 & $1,026,828^{1}$ & 8170 & - & - & - \\
\hline No BESS & 206,748 & 542,179 & 4558 & 184,537 & 484,649 & 3612 \\
\hline Limited BESS & 109,927 & 288,172 & 2488.84 & 281,358 & 738,656 & 5681 \\
\hline Optimized BESS & 28,719 & 75,170 & 860.31 & 362,566 & 951,658 & 7310 \\
\hline
\end{tabular}

${ }^{1}$ The $\mathrm{CO}_{2}$ emissions were calculated by simulating the present system, with the present consumption, in HOMER PRO.

Table 4. Comparison of the economics of the different plants.

\begin{tabular}{|c|c|c|c|c|c|c|c|c|c|}
\hline Solutions & Diesel Gen. (kW) & Capex (\$) & PV (kWp) & BESS (kWh) & Wind Farm $(\mathrm{kW})$ & Fuel Consumption (L/year) & Diesel and $O$ \& M (\$/year) & $\operatorname{COE}(\$ / \mathrm{kWh})$ & NPC (\$) \\
\hline Present & 410 & 0 & 30 & - & 60 & 391,285 & 578,681 & 0.46 & $10,600,000$ \\
\hline No BESS & $\begin{array}{l}410 \\
100\end{array}$ & $1.35 \mathrm{M}$ & 569 & - & 60 & 206,748 & 285,561 & 0.354 & $7,568,600$ \\
\hline Limited BESS & $\begin{array}{l}410 \\
100\end{array}$ & $2.15 \mathrm{M}$ & 578 & 1328 & 60 & 109,927 & 169,556 & 0.305 & $6,507,321$ \\
\hline Optim. BESS & $\begin{array}{c}410 \\
100 \\
50\end{array}$ & $3.46 \mathrm{M}$ & 808 & 2598 & 60 & 28,719 & 74,740 & 0.253 & $6,179,443$ \\
\hline
\end{tabular}


NPC of the current configuration is higher than hybrid configurations: costs of fuel, O \& M and replacement are larger for generators. In the hybrid configurations, the $\mathrm{O} \& \mathrm{M}$ costs are lower than the current one thanks to a reduction in fuel consumption. This difference influences the COE of the four configurations: COE of hybrid plants is lower than present plant: $0.354 \$ / \mathrm{kWh}, 0.305 \$ / \mathrm{kWh}$ and $0.253 \$ \mathrm{kWh}$ versus $0.46 \$ / \mathrm{kWh}$.

The three proposed solutions can guarantee a relevant cost reduction but there are differences between the solution with and without BESS.

Figure 8 shows the net present costs summary of the three solutions. The solution without BESS has a lower Capex but high fuel costs due to the larger use of the diesel generators, whereas the solutions with BESS have lower fuel costs, which are the most variable, but the $\mathrm{O} \& \mathrm{M}$ costs are higher due to the BESS replacement cost, which grows with the storage capacity.

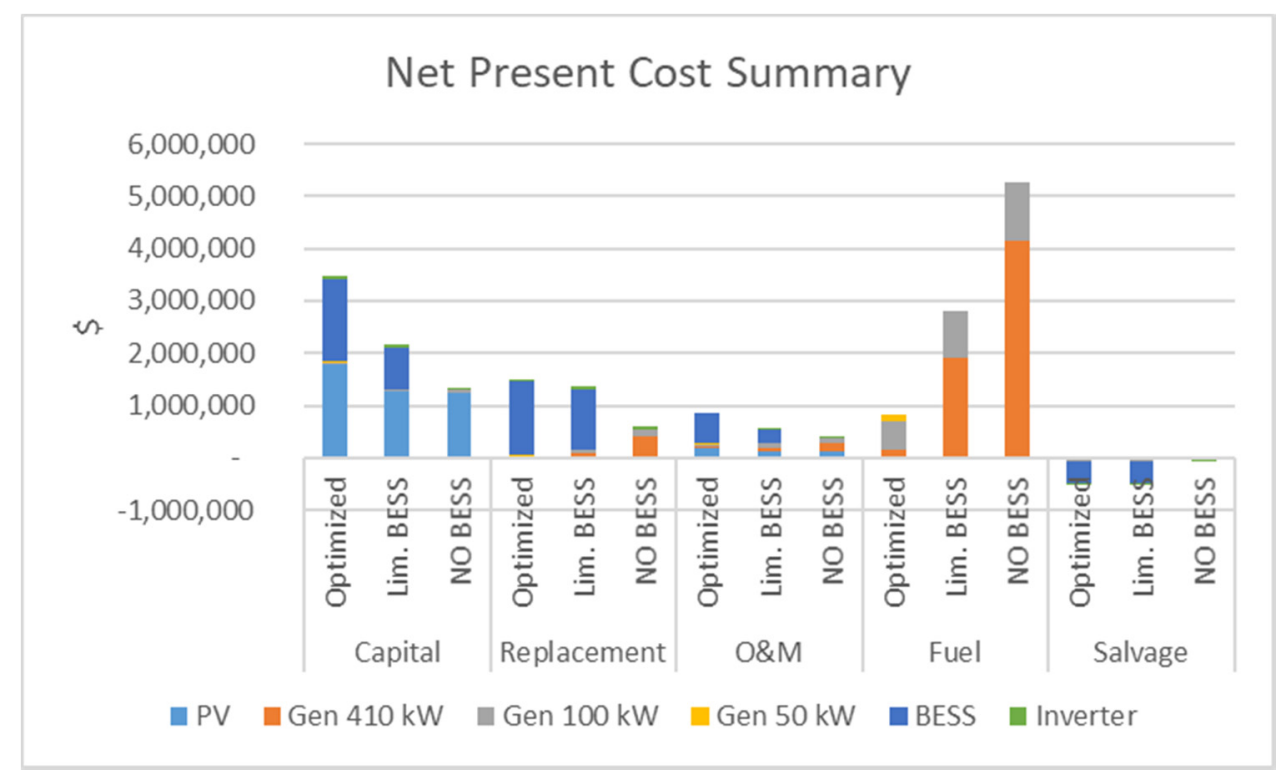

Figure 8. Net present cost summary.

Without a sufficient initial financial means, the solution without BESS is the best solution, as it reduces the COE but it is still highly dependent of the fuel price variability. The solutions with BESS have a lower dependence of the fuel price, but a higher capital cost.

\subsection{Sensitivity Analysis}

In this section, various sensitivity analyses have been performed on the hybrid diesel/PV system with optimized BESS. The variated parameters of this study are: cost of diesel prices, load consumption and BESS cost.

The considered diesel prices are the annual average price of diesel of three most representative years of the first five years of operation of the mini grid, i.e., $1.28 \$ / \mathrm{L}, 0.81 \$ / \mathrm{L}$, and $1.00 \$ / \mathrm{L}$, and two higher value to analyze two negative situations, i.e., $1.50 \$ / \mathrm{L}$ and $2.00 \$ / \mathrm{L}$.

Since the optimized configuration provide a large use of renewable sources of the optimized configuration (around 91\% for the base case), the diesel price variation has a low impact on the $\mathrm{NPC}, \mathrm{COE}$ and the renewable penetration in the system with maximum variation of $7 \%, 7 \%$ and $3 \%$, respectively (Figure 9). This confirms that the scenario with a high penetration of renewable energy makes the plant costs quite insensitive on the unpredictable and uncontrollable price variation of fossil fuels. On the other hand, configurations relying mainly on diesel consumption will be more vulnerable to sudden increases in fuel price. 


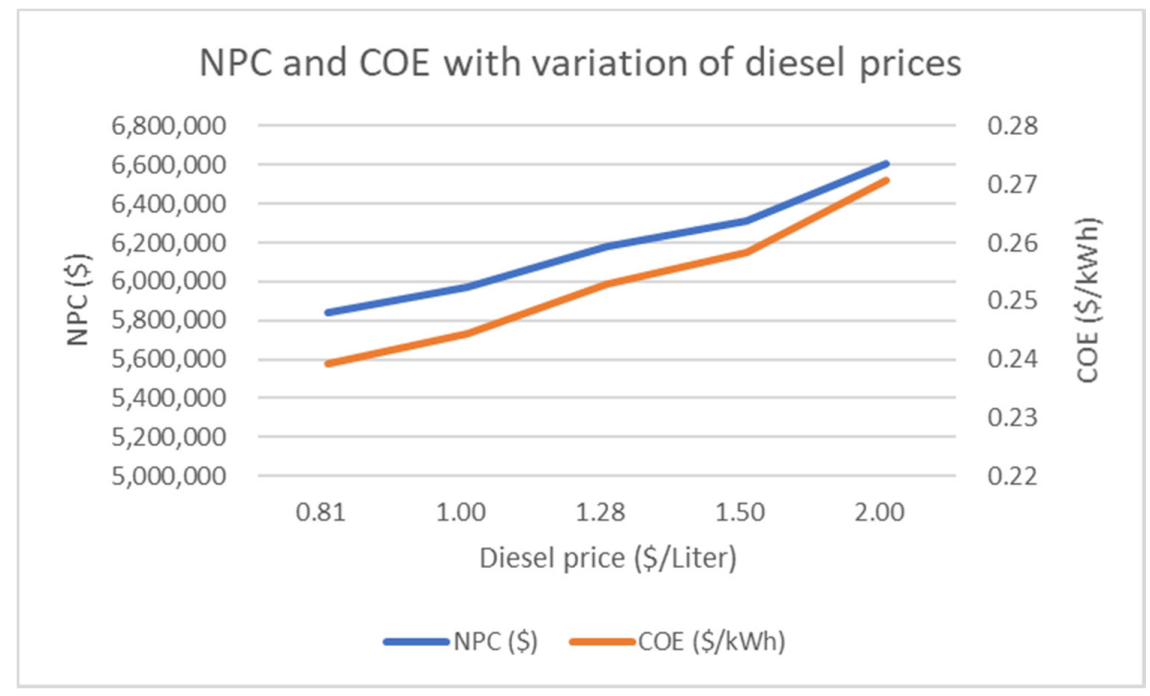

Figure 9. NPC (Net Present Cost) and COE (Cost Of Energy) with variation of diesel prices.

To explore the variation of load, there have been considered three different scenarios based on collected data: 2658,2944 , and $3268 \mathrm{kWh} /$ day, which represent the average daily load consumption of 2013, 2014 and 2015, respectively.

Figure 10 shows the economical parameters variations as a function of the daily load and the fuel price. With the range here considered, the $\mathrm{COE}$ (points and superimposed numbers) varies from 0.232 to $0.281 \$ / \mathrm{kWh}$. The produced renewable energy fraction varies from $94.4 \%$, when the scaled average load is $2658 \mathrm{kWh}$, to $86 \%$, when the scaled average load is $3268.22 \mathrm{kWh}$, which is due to the larger use of diesel when the load consumption increases. COE and NPC (colors) variation depends mainly on the fuel price variation, while the load consumption increasing can cause a maximum variation of $8 \%$ of the COE (scenario with diesel fuel price at $0.81 \$ / \mathrm{L}$ ), the diesel price variation can cause a maximum variation of $17 \%$ (scenario with scaled average load at $3268.22 \$ / \mathrm{L}$ ).

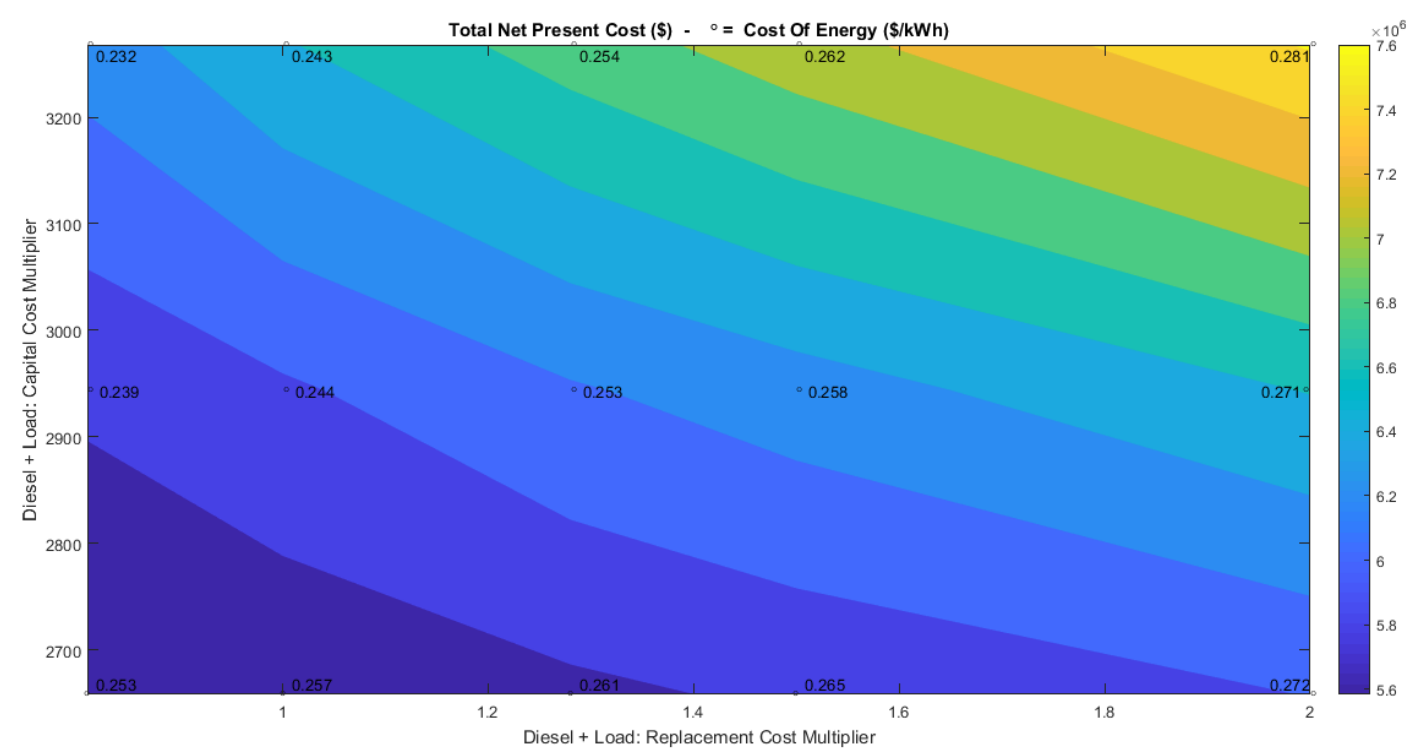

Figure 10. Effect on varying electric load and diesel fuel price on the COE and the NPC superimposed COE-surface NPC.

The variation of BESS cost affects the NPC and the COE linearly. Thanks to the development of passenger electric vehicles market, the Li-Ion battery price has decreased strongly during recent 
years and is expected to decrease more in the next few years [35]. Thus, there have been explored the effects of capital and replacement costs of batteries reduced up to $50 \%$ of the base case cost, which is $600 \$ / \mathrm{kWh}$.

Figure 11 shows that the $\mathrm{COE}$ (points and superimposed numbers) decreases from a maximum of $0.253 \$ / \mathrm{kWh}$ to $0.200 \$ / \mathrm{kWh}$, for the decrease of capital and replacement costs here considered. A strong reduction can also be noticed for the NPC, which decreases from about $\$ 6.2$ million to about $\$ 4.9$ million (colors).

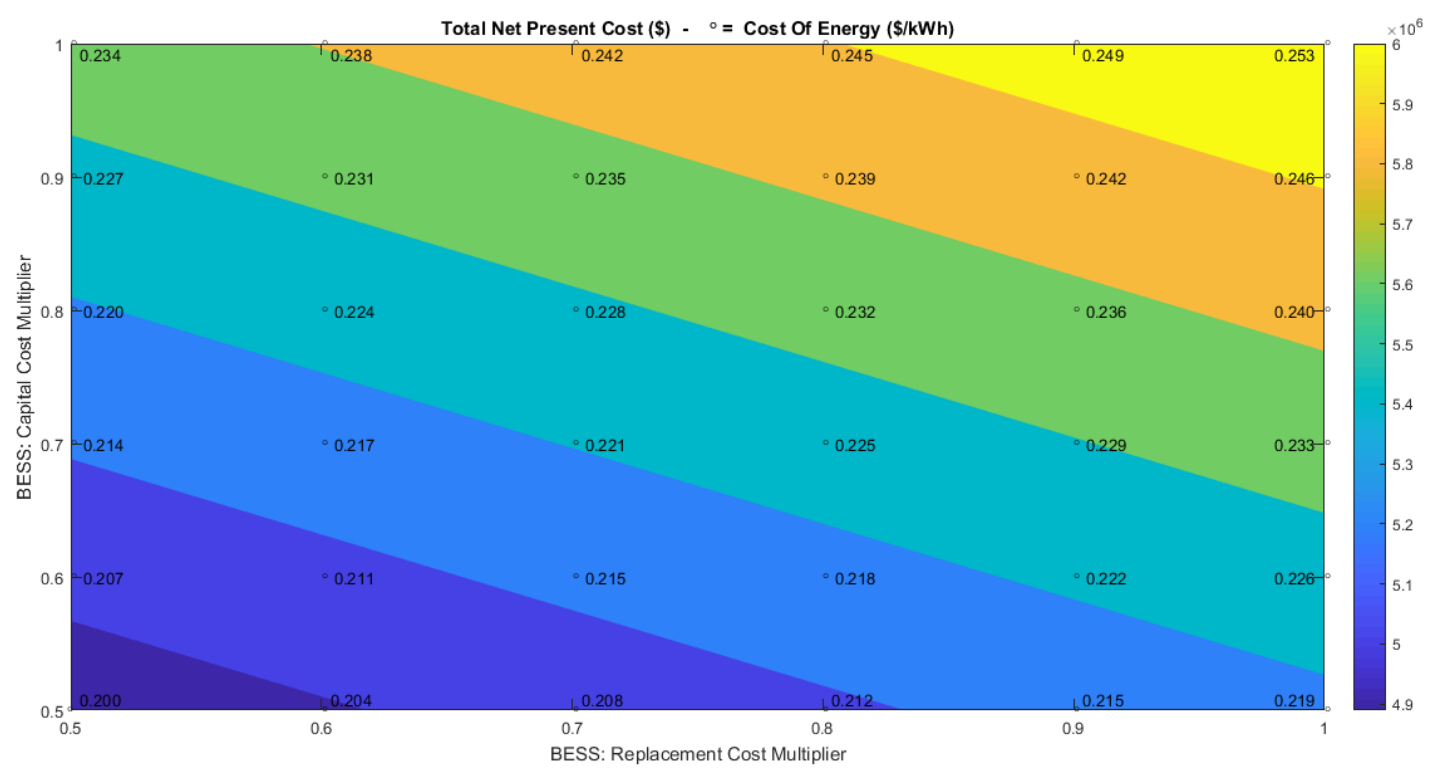

Figure 11. Effect on varying BESS capital and replacement costs multiplier on the COE and the NPC superimposed COE-surface NPC.

Considering no reduction of the capital cost of BESS and reducing only the replacement costs, the NPC reduces from $\$ 6,179,433.19$ to $\$ 5,712,753.71$, and the COE reduces from $0.253 \$ / \mathrm{kWh}$ to $0.234 \$ / \mathrm{kWh}$ (Figure 12). This means that, in our base configuration, a reduction of $50 \%$ of replacement batteries costs could reduce COE and NPC by $8 \%$ approximatively.

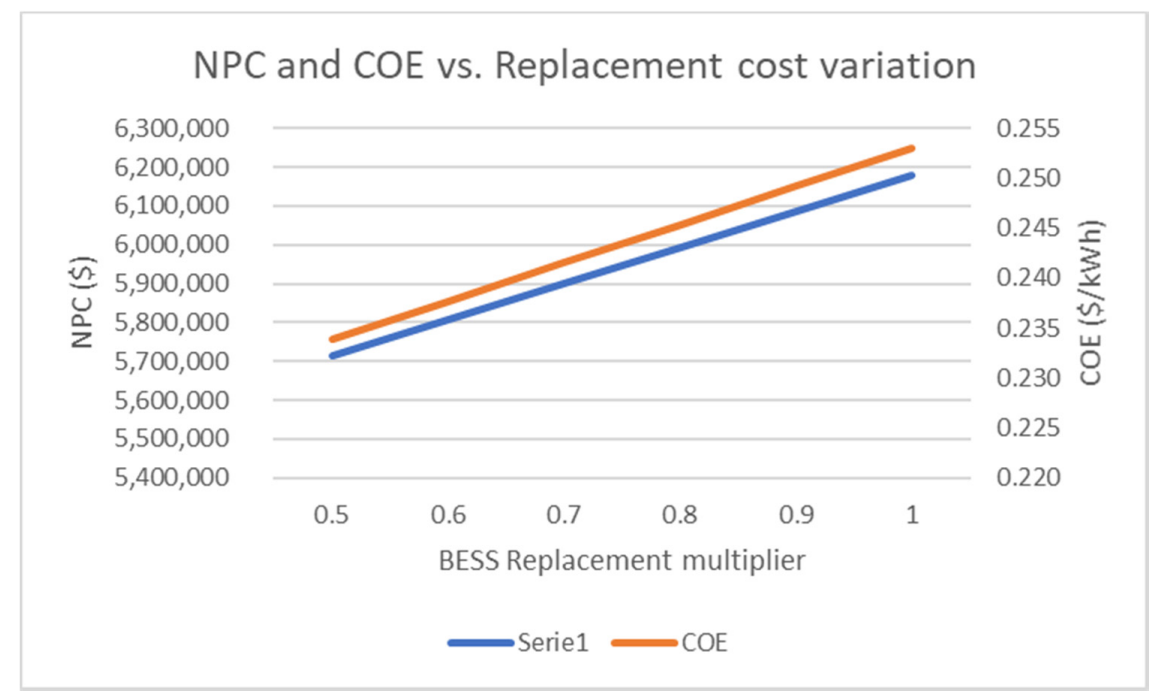

Figure 12. NPC and COE with variation of BESS replacement multipliers. 


\subsection{Comparison with a Probabilistic Approach}

The mini-grid under investigation was then sized using an optimization tool that performs a probabilistic simulation of the operation of different possible size scenarios [11,36]. With this approach, the mini-grid is basically sized by searching the set of components whose yearly operation is expected to be the cheapest one, accounting both for CAPEX and OPEX. Operational costs include fuel charges, maintenance costs and the economic value of load curtailment. More in detail:

- An external Particle Swarm Optimization (PSO) procedure properly selects possible size scenarios of different components of the mini-grid.

- A year of operation is simulated several times according to a Sequential Monte Carlo procedure.

- Simple load following procedures are simulated to be used in real time to balance the system.

- The yearly OPEX of the current size scenario are evaluated, as the average operational costs obtained in the different Monte Carlo simulations.

- The Net Present Cost (NPC) of the current size scenario is assessed, based on its CAPEX and OPEX.

- When the PSO converges, the size scenario with the lowest NPC is chosen as the best design of the mini-grid.

The results shown in Table 5 confirm the robustness of the sizing proposed in the previous sections, since the outcomes of the two models are very similar. The optimal sizes of the inverter and of the battery, as well as the additional capacity of the diesel generator, are in fact very close to the ones calculated with HOMER. The small deviations relevant to the optimal size of the battery and to the NPC are due to the slight differences existing between the dispatching strategies of the two tools. In fact, HOMER schedules the generators to meet the total demand and ensure an extra operating reserve of $10 \%$ of the load, which slightly increases the NPC of the mini-grid; conversely, the sizing strategy described in [36] is explicitly aimed at minimizing the NPC, which includes the cost of load curtailment. In rural areas of developing countries, the economic value of unserved energy is relatively low (around $1 € / \mathrm{kWh}$ ), so, in the case under examination, the best trade-off between CAPEX, OPEX and system reliability turns out to correspond to a small amount of load curtailment $(0.4 \%$ of the yearly demand). The corresponding NPC, including the cost of unserved energy, is lower than in HOMER, without significantly affecting the continuity of supply.

Table 5. Optimal size of the system with the probabilistic method described in [36].

\begin{tabular}{cccccc}
\hline Method & NPC (M\$) & PV (kW) & Battery (kWh) & Inverter (kW) & Diesel Gen. (kW) \\
\hline HOMER PRO 3.10.1 & 6.2 & 808 & 2598 & 202 & $410+100+50$ \\
Stochastic optimization & 5.7 & 865 & 2066 & 208 & 136 \\
\hline
\end{tabular}

To evaluate the benefits of using a predictive operational strategy instead of the simple load-following procedures implemented in HOMER and in [36], the mini-grid described in the last row of Table 5 was then re-simulated assuming a rolling-horizon infra-daily redispatching strategy of the batteries and of the diesel generator [11]. With this method, every $6 \mathrm{~h}$, the load and the PV power profiles expected for the following $24 \mathrm{~h}$ are used by a MILP procedure that optimizes the use of batteries and of the diesel generator for the hours to come, by minimizing short-term operational costs; the capability constraints of power electronics, battery, diesel generator, renewable sources and fuel tank are duly taken into account. During the simulation of the real time, the Monte Carlo procedure obviously draws possible hourly deviations from expected load/PV patterns and priority rules balance the system. The major outcomes of introducing a predictive dispatching strategy are the notable reduction of load curtailment (about $-90 \%$ ) and the more efficient use of the diesel generator, whose capacity utilization factor increases on average from $65 \%$ to $81 \%$; both effects contribute to additionally reduce OPEX by $3 \%$ and NPC by $1 \%$. 


\section{Conclusions}

This paper studied some technical, environmental and economic aspects of solutions that can be applied in rural areas without access to electricity in developing countries [37]. We have considered the case study of the community of Habaswein, Kenya, where an off-grid diesel generator supplies energy with a partial contribution of a PV plant and a wind farm.

The present plant performances were studied and the main characteristics and problems of the plant highlighted:

- There is a growing energy demand recorded: The number of connections has almost tripled from the start-up of the mini-grid and there is a constant growth of energy production.

- The energy production supplied by the diesel generator is dominant with large emissions of GHG and other pollutants.

- The energy production cost is high and is subjected to many variations due to operation condition of the plant.

The HOMER PRO software was used to carry out the study of the optimization of the present plant, through which various adoptable solutions have been studied, by applying fully renewable or hybrid configurations. Technical and operational values have been evaluated for each solution, and, subsequently, the most cost-effective solutions have been chosen and compared with the present plant.

As result of this study, three different solutions to compare were selected: one with limited storage, one with storage optimized by Homer Pro and one without storage.

The optimized solution was validated by a comparison with a stochastic optimization model.

The criteria applied to drive technical solutions were the following:

- Capital cost: The solution without storage has a lower initial cost.

- Operational cost: The solution with storage needs less fuel so the yearly cost of the plant will be lower and will be less subjected to the fuel price variations.

- Dependency on the fuel price: The fuel price is the expense that drives the cost of the plant during his life, it is variable and it is difficult to make prevision on its variation during the years.

- Environmental cost: The solution with storage needs less fuel which is the origin of the pollutants and GHG emissions.

Moreover, a sensitivity analysis was carried out to analyze different possible scenarios: variation of cost of diesel prices and of load consumption, reduction of BESS Capital and Replacement costs.

This study's results show that all the selected optimization solutions can improve the current plant. The main common aspects can be summarized as follows:

(1) Considering 25 years plant lifetime, hybrid configurations are more convenient in comparison with non-renewable configurations, such as the base case. In fact, the hybrid solutions have a lower NPC than the base case and that influences the COE of every configuration: the solutions with BESS vary their COE from 0.253 to $0.305 \$ / \mathrm{kWh}$, about $43 \%$ less than base case COE.

(2) Hybrid solutions are more competitive at the economic level, compared to non-renewable solutions, as well as in developing countries, with weak economies and where factors such as inflation and real interest rate are unpredictable. This kind of solutions help to save money, as reported in the economic evaluation, that could be used differently, for instance investments in local enterprises and social goods;

(3) Hybrid solutions enable saving fuel and hence reduction of local pollution, responsible for health problems, especially at a domestic level. Greenhouse gas emissions savings of tens to hundreds of tons of $\mathrm{CO}_{2}$ every year, compared with alternative solutions based on fossil fuels, could be achieved. Thus, overall, the use and diffusion of renewable energy in developing countries, instead of traditional energy systems, represents a strong contribution to reach the objectives of greenhouse emission reduction, set by the international community in the COP21 of Paris. 
Given the fast decrease in prices of renewable technologies and storage, this study further proves that new off-grid solutions can be conceived from the beginning as relying on renewable energy only. In this case, the possible use of traditional generators would be as a back-up only, in the case of extraordinary maintenance, exceptionally long periods of low irradiation or temporary high demand.

Acknowledgments: This paper was possible thanks to RES4Africa, nonprofit association, especially Roberto Vigotti, as they allowed the first on site mission, and Marco Aresti and Saverio Frullani, who participated in the field study to collect and elaborate data.

Author Contributions: Isaac Nzue Kiva, Andrea Micangeli and Jeremiah Kiplagat collected field data and information on Kenya state of the art in rural electrification. Valeria Gambino and Isaac Nzue Kiva wrote the literature review section. Riccardo Del Citto performed the power plant design optimizations with HOMER PRO; Simone Giovanni Santori and Riccardo Del Citto analyzed the collected data; Andrea Micangeli, Riccardo Del Citto, Isaac Nzue Kiva and Daniele Viganò wrote the paper; Andrea Micangeli and Isaac Nzue Kiva suggested the study idea and shared in writing and revising the paper. Davide Fioriti and Davide Poli performed the simulations with the probabilistic sizing method and compared the outcomes with the Homer's results. Daniele Viganò revisited carefully the results and proposed technical solutions and, with Riccardo Del Citto, wrote the conclusions.

Conflicts of Interest: The author declares no conflicts of interest.

\section{References}

1. Climatescope 2016. Kenya. Available online: http://global-climatescope.org/en/country/kenya/\#/details (accessed on 28 July 2017).

2. Kiplagat, J.K.; Wang, R.Z.; Li, T.X. Renewable energy in Kenya: Resource potential and status of exploitation. Renew. Sustain. Energy Rev. 2011, 15, 2960-2973. [CrossRef]

3. Kenyatta, U.; Ruto, W.; Ngilu, C.; Balala, N. Harmonised Jubilee Coalition Manifesto: Agenda for Kenya 2013-2017 and beyond; Jubilee Coalition: Nairobi, Kenya, 2013.

4. Pérez-Arriaga, I. New regulatory and business model approaches to achieving universal electricity access. Papeles de Energia 2017, 3, 37-77.

5. Mandelli, S.; Barbieri, J.; Mereu, R.; Colombo, E. Off-grid systems for rural electrification in developing countries: Definitions, classification and a comprehensive literature review. Renew. Sustain. Energy Rev. 2016, 58, 1621-1646. [CrossRef]

6. Bernal-Agustín, J.L.; Dufo-López, R. Simulation and optimization of stand-alone hybrid renewable energy systems. Renew. Sustain. Energy Rev. 2009, 13, 2111-2118.

7. Shaahid, S.M.; El-Amin, I. Techno-economic evaluation of off-grid hybrid photovoltaic-diesel-battery power systems for rural electrification in Saudi Arabia-A way forward for sustainable development. Renew. Sustain. Energy Rev. 2009, 13, 625-633. [CrossRef]

8. Al-Karaghouli, A.; Kazmerski, L.L. Optimization and life-cycle cost of health clinic PV system for a rural area in southern Iraq using HOMER software. Sol. Energy 2010, 84, 710-714. [CrossRef]

9. Nema, P.; Nema, R.K.; Rangnekar, S. A current and future state of art development of hybrid energy system using wind and PV-solar: A review. Renew. Sustain. Energy Rev. 2009, 13, 2096-2103. [CrossRef]

10. International Renewable Energy Agency (IRENA). Evaluating Renewable Energy Policy: A Review of Criteria and Indicators for Assessment. Int. Renew. Energy Agency, 2014; pp. 36-44. Available online: http:/ /www.irena.org/ -/media/Files/IRENA/Agency/Publication/2014/Evaluating_RE_Policy.pdf (accessed on 17 August 2017).

11. Fioriti, D.; Giglioli, R.; Poli, D.; Lutzemberger, G.; Vanni, A.; Salza, P. Optimal sizing of a hybrid mini-grid considering the fuel procurement and a rolling horizon system operation. In Proceedings of the IEEE International Conference on Environment and Electrical Engineering and 2017 IEEE Industrial and Commercial Power Systems Europe (EEEIC/I\&CPS Europe), Milan, Italy, 6-9 June 2017; pp. 1-6.

12. Bhattacharyya, S.C. Review of alternative methodologies for analysing off-grid electricity supply. Renew. Sustain. Energy Rev. 2012, 16, 677-694. [CrossRef]

13. Rojas-Zerpa, J.C.; Yusta, J.M. Application of multicriteria decision methods for electric supply planning in rural and remote areas. Renew. Sustain. Energy Rev. 2015, 52, 557-571. [CrossRef]

14. Domenech, B.; Ferrer-Martí, L.; Pastor, R. Hierarchical methodology to optimize the design of stand-alone electrification systems for rural communities considering technical and social criteria. Renew. Sustain. Energy Rev. 2015, 51, 182-196. [CrossRef] 
15. Zhou, W.; Lou, C.; Li, Z.; Lu, L.; Yang, H. Current status of research on optimum sizing of stand-alone hybrid solar-wind power generation systems. Appl. Energy 2010, 87, 380-389. [CrossRef]

16. Fioriti, D.; Giglioli, R.; Poli, D. Short-term operation of a hybrid minigrid under load and renewable production uncertainty. In Proceedings of the IEEE Global Humanitarian Technology Conference: Technology for the Benefit of Humanity, Seattle, WA, USA, 13-16 October 2016.

17. Mandelli, S.; Merlo, M.; Colombo, E. Novel procedure to formulate load profiles for off-grid rural areas. Energy Sustain. Dev. 2016, 31, 130-142. [CrossRef]

18. Yuan, S.; Kocaman, A.S.; Modi, V. Benefits of forecasting and energy storage in isolated grids with large wind penetration-The case of Sao Vicente. Renew. Energy 2017, 105, 167-174. [CrossRef]

19. Akikur, R.K.; Saidur, R.; Ping, H.W.; Ullah, K.R. Comparative study of stand-alone and hybrid solar energy systems suitable for off-grid rural electrification: A review. Renew. Sustain. Energy Rev. 2013, 27, 738-752. [CrossRef]

20. Luna-Rubio, R.; Trejo-Perea, M.; Vargas-Vazquez, D.; Rios-Moreno, G.J. Optimal sizing of renewable hybrids energy systems: A review of methodologies. Sol. Energy 2012, 86, 1077-1088. [CrossRef]

21. Baños, R.; Manzano-Agugliaro, F.; Montoya, F.G.; Gil, C.; Alcayde, A.; Gòmez, J. Optimization methods applied to renewable and sustainable energy: A review. Renew. Sustain. Energy Rev. 2011, 15, 1753-1766.

22. Sinha, S.; Chande, S.S. Review of software tools for hybrid renewable energy systems. Renew. Sustain. Energy Rev. 2014, 32, 192-205. [CrossRef]

23. Bekele, G.; Tadesse, G. Feasibility study of small Hydro/PV/Wind hybrid system for off-grid rural electrification in Ethiopia. Appl. Energy 2012, 97, 5-15. [CrossRef]

24. Kenfack, J.; Neirac, F.P.; Tamo Tatietse, T.; Mayer, D.; Fogue, M.; Lejeune, A. Microhydro-PV-hybrid system: Sizing a small hydro-PV-hybrid system for rural electrification in developing countries. Renew. Energy 2009, 34, 2259-2263. [CrossRef]

25. Kanase-Patil, A.; Saini, R.; Sharma, M. Integrated renewable energy systems for off grid rural electrification of remote area. Renew. Energy 2010, 35, 1342-1349. [CrossRef]

26. Connolly, D.; Lund, H.; Mathiesen, B.V.; Leahy, M. A review of computer tools for analysing the integration of renewable energy into various energy systems. Appl. Energy 2010, 87, 1059-1082. [CrossRef]

27. Lilienthal, P.; Lambert, T.; Gilman, P. Computer Modeling of Renewable Power Systems. Encycl. Energy 2004, $1,633-647$.

28. Lambert, T.; Gilman, P.; Lilienthal, P. Micropower System Modeling with Homer. Integration of Alternative Sources of Energy. 2006, pp. 379-418. Available online: http:/ /homerenergy.com/documents/ MicropowerSystemModelingWithHOMER.pdf (accessed on 15 July 2017).

29. HOMER Energy LLC. Available online: http://www.homerenergy.com/HOMER_pro.html (accessed on 25 Auguest 2017).

30. Alsharif, M.H. A Solar Energy Solution for Sustainable Third Generation Mobile Networks. Energies 2017, 10, 429. [CrossRef]

31. NASA. Available online: https:/ / eosweb.larc.nasa.gov/sse/ (accessed on 8 Auguest 2017).

32. Bradbury, K.; Pratson, L.; Patiño-Echeverri, D. Economic viability of energy storage systems based on price arbitrage potential in real-time U.S. electricity markets. Appl. Energy. 2014, 114, 512-519. [CrossRef]

33. Central Bank of Kenya. Available online: https:/ / www.centralbank.go.ke/ (accessed on 8 Auguest 2017).

34. The World Bank Data. Available online: https://data.worldbank.org/ (accessed on 2 September 2017).

35. Claire, C. Lithium-ion Battery Costs and Market. Bloomberg New Energy Finance, 5 July 2017. Available online: https:/ / data.bloomberglp.com/bnef/sites/14/2017/07 / BNEF-Lithium-ion-battery-costsand-market.pdf (accessed on 15 November 2017).

36. Fioriti, D.; Giglioli, R.; Poli, D.; Lutzemberger, G.; Vanni, A.; Salza, P. Optimal sizing of a mini-grid in developing countries, taking into account the operation of an electrochemical storage and a fuel tank. In Proceedings of the International Conference on Clean Electrical Power (ICCEP), Santa Margherita Ligure, Italy, 27-29 June 2017.

37. Gualberti, G.; Alves, L.; Micangeli, A.; da Graça Carvalho, M. Electricity privatizations in Sahel: A U-turn? Energy Policy 2009, 37, 4189-4207. [CrossRef]

(C) 2017 by the authors. Licensee MDPI, Basel, Switzerland. This article is an open access article distributed under the terms and conditions of the Creative Commons Attribution (CC BY) license (http://creativecommons.org/licenses/by/4.0/). 